\title{
The Concept of the Regional Industrial Cluster Information Support
}

\section{Aleksandra N. Nikolayeva}

Chuvash State Pedagogical University named after I.Y. Yakovlev, Cheboksary, Russia Email: e_a_antipova@mail.ru

Tatiana V. Khalilova

Kazan (Volga region) Federal University, Kazan, Russia

Vera P. Rukomoinikova

Volga State University of Technology, Yoshkar-Ola, Russia

Yuri I. Litvin

Financial University under the Government of the Russian Federation, Moscow, Russia

Guzyal M. Kharisova

Kazan State University of Architecture and Engineering, Kazan, Russia

Iraida D. Tumbaeva

Volga State University of Technology, Yoshkar-Ola, Russia

Inessa V. Lebedeva

Naberezhnye Chelny Institute of Social-Pedagogical Technologies and Resources, Naberezhnye Chelny, Russia

Doi:10.5901/mjss.2015.v6n2s3p29

\section{Abstract}

One of the priorities and internationally accepted approaches to the management of innovation processes in the global economy is the cluster approach, a product of the integration of economic processes, which is a powerful tool to promote regional development. It has been effectively studied in the article the regional cluster with data items to ensure the effective interaction of all participants in the process of achieving economic goals. The paper presents an algorithm of information modeling of regional industrial cluster, comprising the steps of determining the hierarchical structure of the processes, the organization of all kinds of flows, the description of the logical structure and the information needs of each process. This article is intended for economists, researchers, enterprises executives, professionals in the field of information technology, dealing with information support of manufacturing processes.

Keywords: regional industrial cluster; modeling; information support; process approach; information model.

\section{Introduction}

\subsection{Background}

A characteristic feature of the modern development of the Russian economy is the creation of industrial clusters, a set of interrelated companies and related educational and management structures, as a means of ensuring sustainable development of the country regions, forming the basis for economic and political management (Shalmina, 2008; Vakorin,2013). The assembly of the end-product, making its constituent parts and components should have a cluster, local character, while reducing production costs and improving the quality and performance of the final product. The 
development of Russian production in the new economy lies in finding strategic partners, a transfer of technologies and further clustering of companies producing the end-product with new technologies and requirements, manufacturers of materials, service, financial and scientific companies, forming a regional industrial cluster (Tsikhan, 2003). Creative activity of clusters consists in the fact that most of their members do not compete directly with each other, but serve different segments of the industry.

\subsection{Status of a problem}

To improve the competitiveness of the region on the basis of the cluster approach requires specific strategy for the development of an existing or projected industrial cluster, concentration of factors and resources that give a competitive advantage through the development of high-tech industry. Regional clusters are the base points of market growth for the sector of the state economy, they increase, in particular, the international competitiveness of the country. Currently, a cluster policy in the Russian Federation is at the stage of formation and development. The cluster theory was considered most completely in the works of the American scientist M.Porter (Porter, 2006), there also may be distinguished scientific works of foreign and domestic scholars (Jones, 2006; Feser,1998; Titov, 2009 and others.).

At the same time, despite the availability of works in the field of development of the clusters theory, many issues of structuring and evaluation of the economic information, creation of clusters information support remain currently almost unexplored. The number of cluster subjects, its employees, resource availability, customer intimacy, competitors, as well as suppliers of components, materials and services - is only a part of the factors contributing to the development of clusters and regions in which they are located. No less important role play the flows of information, its transparency, a unique standardization system of activities of subjects of cluster relations and business processes (Pogodina, Zadorova, 2009; Nigmetzyanova, 2011; Sirazetdinov, 2010; Tatarkin, Lavrikova, 2008).

\subsection{Analysis of foreign experience in the field of development of regional industrial clusters}

Analyzing foreign experience of regional industrial clusters functioning: (the USA (computer, automobile, an entertainment cluster), Canada (biotech, a high-tech cluster), United Kingdom (biopharmaceutical, educational), France (perfumery and cosmetics, food), Switzerland (biotechnological, financial), Finland (forest, a cluster of information and communication technologies, energy, metallurgy, machine building), India (a cluster on the production of woven and knitted fabrics, food, machine-tool, a leather production cluster, pharmaceutical), China (automobile, high-tech, a steel production cluster, electro -technical, a cluster for the production of mobile phones), Japan (electro -technical, automobile, an information technology cluster, biotechnological), one can systematize an extensive experience in the development of competitive clusters in a sustainable competitive advantage over other regions due to higher productivity, innovation development and new types of businesses (Evstigneeva, Evstigneev, 2004; Tatarkin, 2008). Two main models of cluster policy function in the economic development of clusters: the Anglo-Saxon (the USA, the UK, Australia) - this is a market model in which the role of the federal government is to reduce the barriers and to form a method of operation of the regional authorities and key clusters stakeholders; the continental model (Japan, Republic of Korea, Singapore, Sweden, France and others.) in which a federal policy plays a crucial role in the development of clusters.

It seems necessary that such structured information support to exist, that would allow to identify and diagnose the condition of all the components of the regional industrial cluster at any point of time. Such interaction requires a special structural organization of information support of all processes of the cluster, using the mechanism of standardization, and information technology at all stages of the product life cycle, from design and manufacturing to modernization and recycling of the industrial end-product.

\section{Materials and Methods}

\subsection{Conceptual provisions of the process approach to the business process modeling}

The proposed by authors (Kovalev, Kovalev, 2009) the treatment of the process approach allows us to formulate the notion of processes for the regional industrial cluster as a stream of activity of each regional industrial cluster subject, the result is a final product that represents value for the consumer.

Thus, the activity of any subject of the regional industrial cluster can be described by a set of business processes, regardless of the type of goods or services produced. This definition is specified in Vakorin's materials (Vakorin, 2006), which state that the set of enterprise activities should bring satisfaction from the end-product to the customer. In this 
context the "customer" means the person who receives the results of the process. In our case, within reviewing the regional industrial cluster activities, customers of the process can be both external (consumers of goods or services) and internal (the next process in the cluster processes network).

Certainly, the process approach is not just a description of the sequence of actions to transform something, here except the technology of certain business processes performing must be initially determined the "owner" who is responsible for the effectiveness of the process (ISO terminology), as well as requirements to the resources (personnel, equipment, tools, production environment, information, etc.), the criteria for the process effectiveness evaluation and the satisfaction of its customers.

The process approach implements the transition to the resource-saving organizational structure (Lean production) (Womeck, Jones, 2006) of the regional industrial cluster which allows you:

- to reduce the number of levels of decision-making by increasing the performers' responsibility in each of the selected business processes;

- to improve the quality of products or services, and the enterprise activity as a whole by means of orientation on the end-product and customer satisfaction;

- to operate successfully in a dynamic market with effective use of budgeting and management accounting principles, as the production restructuring is carried out within the only one structural unit of the regional industrial cluster;

- to automate the technology of business processes execution of the regional industrial cluster by creating the information support of processes.

\subsection{The use of the process approach to the design of the regional industrial cluster}

To create an information support of the regional industrial cluster in compliance with the properties of integrity, completeness, relevance of economic information it is necessary to:

1. Select the basic processes of the regional industrial cluster;

2. Define the boundaries of the business processes of the regional industrial cluster;

3. Set the "process owner", i.e. the official who is responsible for the progress and results of the process - and he/she will be a source and a recipient of economic information of the regional industrial cluster;

4. Identify the procedure or the established way of doing business process (documentation describing the technology of works or indicators of a process);

5. Ensure the necessary and sufficient number of control points (or matching) inside the business process through the process indicators - statistical data about the efficiency and performance of the process and evaluation of process customer satisfaction.

\subsection{The definition of the regional industrial cluster processes}

In the scientific literature (Repin, Eliferov, 2006; Sirazetdinov, Brazhkina, 2010 and others) it is indicated that all the processes of the organization are divided into four types: management processes, core processes (life cycle processes), the processes of resources provision and processes of measurement, analysis and improving. Analyzing the economic cluster processes outlined in the article, let's define the basic processes of the regional industrial cluster in accordance with the nature of the enterprises activities - subjects of the cluster:

- $\quad$ The production process of the end-product;

- The process of resources delivery to produce the end-product;

- $\quad$ The process of the end-product marketing;

- The process of developing knowledge-intensive production technologies and personnel training for the regional industrial cluster, that is, science and education.

On the basis of the distinguished basic processes of the regional industrial cluster further there will be carried out a documentation of the process, i.e. it will be done the accountancy of its inputs and outputs, the mechanisms of functioning, the necessary resources, the system of indicators and will be developed the infological model based on the selected methodology of the process modeling, will be defined performance indicators and activities efficiency of the regional industrial cluster. 


\section{Results}

\subsection{Analysis of the dynamics of the regional industrial cluster}

Integration of different organizations into the industrial cluster is motivated by the agreed requirements to suppliers and dealers, reducing costs on the implementing of new production technologies by means of production output, increase of the potential market for engineering and consulting services, including for small businesses, through the introduction of subcontracting in the performance of complex projects and programs, increase the ability of enterprises, including small ones, to attract investments and grants; a more effective system of access to foreign partners and new markets, as well as absolute extension of access to information on the market needs and small businesses products and services promotion to the market of large enterprises.

The union into the cluster, based on the integration, forms not a random concentration of a variety of scientific and technological inventions, but a certain system of dissemination of new knowledge and technologies. In this case, the most important condition for the effective transformation of inventions into innovations and innovations into competitive advantages is the formation of a network of sustainable information links between all cluster members. Their creation is extremely important for transition of the economy on an innovative way of development; that requires constant information contacts of innovation process participants, allowing to adjust the research, the experimental development and the production process.

Such interaction requires special structural organization of information support of all processes of the cluster using the mechanism of standardization and information technologies at all stages of the product life cycle, from design and manufacturing to modernization and recycling of the end-product production.

\subsection{The structuring of the regional industrial cluster economic information based on the process approach}

It is necessary to determine the type of objectives, a methodic of their solution and the necessary amount of economic information for developing cluster structures in the regional economy. Grouping of objectives of cluster policy is given in a table 1.

Table 1. Ways of solving regional cluster policy objectives

\begin{tabular}{|c|c|}
\hline Objectives & Methods and ways of solving \\
\hline Diagnostics of Clusters & $\begin{array}{l}\text { - Development of the cluster identification methodic } \\
\text { - Development of the cluster competitiveness evaluation methods } \\
\text { - The methodic for priority clusters selecting; } \\
\text { - Priority clusters ranking from the standpoint of regional development }\end{array}$ \\
\hline Cluster Initiatives Maintenance & $\begin{array}{l}\text { - Allocation of the organization-facilitator and contribution to its efforts to form a cluster; } \\
\text { - Promotion of the establishment of the group leaders and organization of workshops } \\
\text { with the participation of the facilitator, the group leaders, representatives of the } \\
\text { authorities; } \\
\text { - Institutionalization of the cluster initiative; } \\
\text { - Development of the cluster vision, areas of its activities, the strategic plan, the action } \\
\text { plan for its implementation; } \\
\text { - Acceptance of the resolution on the Coordinating Council establishment for the } \\
\text { formation and development of the regional cluster, etc .; }\end{array}$ \\
\hline Promotion of Clusters' Development & $\begin{array}{l}\text { - Facilitation of implementation means for the cluster development: } \\
\text { - Organizational assistance in coordinating the cluster members' efforts; } \\
\text { - Support the creation and development of infrastructure; } \\
\text { - Assistance in the personnel training and education; } \\
\text { - Tax and other benefits for the cluster members and others. }\end{array}$ \\
\hline Monitoring of Clusters & $\begin{array}{l}\text { - Creating a system of cluster development indicators and the methodic of its data } \\
\text { collection and analysis; } \\
\text { - Evaluating the cluster effectiveness as a whole and for its individual members; } \\
\text { - A system of clusters efficiency monitoring in the region }\end{array}$ \\
\hline
\end{tabular}

When analyzing the solving methods and forms of each objectives, it is necessary to have such structured information resources that would identify and diagnose the condition of all the components of the regional industrial cluster at any 
time, in other words - the creation of information support (Moiseeva, 2002; Vasiliev, 1994) of the regional industrial cluster would greatly contribute to solving an urgent problem of the regional industrial cluster activity evaluation.

Economic information, included into the information support of the regional industrial cluster at all levels, is very diverse in its content. At the level of enterprises, a component of the regional industrial cluster, they are:

- description of technology and production conditions;

- $\quad$ technical characteristics of the production means (firstly, equipment);

- market conditions (prices, volume of demand);

- data on working capital;

- data on staff;

- data on the availability and resource requirements;

- standards, targets;

- collection of indicators (capital intensity, profitability, cost value);

- various orders, instructions, methodic, etc..

The input information of the regional industrial cluster comes from outside. The part of it, the initial information, comes from the object of management and is obtained by direct measurement or calculation. For cluster subjects engaged in industrial production it is the volume of output, the number of defective goods, the number of workers, the downtime, the stores in the warehouse, etc. The initial information contacts most closely with a particular activity of managed economic units and includes both slowly varying (relatively constant) and operational data.

The internal information of the regional industrial cluster includes regulatory reference, accounting and planned information of all enterprises - that is a component of the cluster.

The receiving of output data should be considered the final result of the regional industrial cluster information processing, the data which are distributed among the subjects of the cluster (for example, the foundation of economic incentives, the volume and structure of investments, reallocation of resources, etc.) and the regional authorities (for example, reporting).

\subsection{The algorithm of the regional industrial cluster information modeling}

Taking into account the information aspect of modeling, considered in this paper, we suggest the following sequence (algorithm) of modeling:

Step 1: Select the basic processes of the upper, middle and lower level of regional industrial cluster functioning based on ISO 9000: 2000. Here on the upper hierarchical level the logic of interaction of regional industrial cluster subjects is described, at the middle level - the interaction of production processes, and then (on the lower level) consumer information technology in the work of individual experts on their work places. Thus the process parameters is the information - process indicators and criteria which help the process "owner" (person in charge) and cluster management to judge the effectiveness of the process and the customer satisfaction of processes results.

Step 2 - Build a tree of processes, including the processes of regional industrial cluster and their hierarchy. At the top level of the tree the business processes are divided into three groups: basic, providing and management.

Step 3: Create a conceptual model of the regional industrial cluster, describing all its subjects, as well as material and information flows. The model is based on the DFD (Data Flow Diagramming) notation and allows reflecting the structural units of the regional industrial cluster and the interaction between them through information flows. The model provides an opportunity to reflect external, towards the system, sources and data destinations, logic functions, flows and data storage to be accessed.

Step 4: Distinguish by $A B C$-analysis significant from the point of view of the modeling purpose the economic information of each of the processes of the upper hierarchical level of the regional industrial cluster quantitative and qualitative indicators, i.e., classify processes indicators according to their importance and significance level. All processes indicators basing on the ranking are divided into categories according to the degree of influence on the final result, the rating is built in order of decreasing importance of the indicator with the distinguishing of groups $A, B$ and $C$.

Step 5: Using the object-oriented approach, we carry out building of the information model of basic processes of the regional industrial cluster through the notation UML (Unified Modeling Language).

In the basis of the proposed approach the processes interaction of the regional industrial cluster is fulfilling through an organized unique information environment (space) containing a specially structured information (knowledge base in the discipline). This approach will enable the construction of a dynamic infological model of the regional industrial cluster.

Step 6: The model reflection through indicative indicators of the processes on the stage of transition from the implementation of previously submitted models to creation of information support for the regional industrial cluster in the 
form of a real information system or a database.

This multi-component modeling in accordance with the above algorithm and obtained at each stage models will let: to create a multidimensional information field (software) of the regional industrial cluster processes; to reflect the current status of the cluster subjects by means of evaluating the significant parameters of the processes; to ensure a real functioning quality system in enterprises - subjects of the cluster as the initial basis for constructing and evaluating is the standard of ISO 9001: 2000 group; to implement the accumulation of statistics on the condition of regional industrial cluster processes and its analysis for operational management and the efficiency increase of regional industrial cluster activity; to define the methodology of qualitative and quantitative measurements and evaluations of the regional industrial cluster processes in order to determine the desired state achievement.

\section{Discussions}

Existing models (logical, production, frame-based, net, object-oriented, special, complex) do not provide all the necessary key requirements (Bashmakov, Bashmakov 2005; Karabutov, 2009; Semakin, 2005), therefore it is necessary to create the model that supports the optimal functioning of regional economic cluster and serves as a basis for the development of an automated system of the cluster management.

Due to description of the regional industrial cluster processes, identification and distinguishing efficiency indicators and performance of its processes, the process owners and regional management structure of industrial clusters receive a single technology of work performance through the description and standardization of process technologies, access to information resources, ensuring transparency of cluster subjects, parameters for the cluster activity evaluation, the mechanism for making management decisions based on an accurate information and facts.

\section{Conclusions}

The structure of the proposed approach to information modeling of the regional economic cluster includes the main processes of the cluster and the relevant parameters of these processes. The presentation form of the model and the level of its detalization is determined by the modeling objectives, this form becomes the criterion for the end of the modeling. The final result of this process is a set of closely interrelated descriptions, since the top-level description of the overall system and ending with the detailed description of parts or operations of the regional industrial cluster.

Thanks to the use of information models and systems of information integration it is provided the effective implementation of business technologies in a single information space, integration and optimization of information interaction of cluster members. In the end, we form a single information space, providing information interaction of the product life cycle participants: design companies, manufacturing companies, suppliers, service organizations and the end user.

\section{Acknowledgments}

The authors thank all participants of this study for their kind cooperation.

\section{References}

Bashmakov, A.I. \& I.A. Bashmakov (2005). Intelligent information technology. Moscow publishing MSTU Bauman: 304.

Evstigneeva, L.P. \& R.N. Evstigneev (2004). Globalization and Regionalism: Lessons for Russia. Journal of Social studies and the present, №1: 118.

Feser, E. (1998). Old and New Theories of Industry Clusters, in Steiner. Clusters and Regional Specialization, Pion Limited. London: 78.

Karabutov, N.M. (2009). Structural identification systems. Analysis of the information structures. Moscow publishing house «LIBROKOM»: 165.

Kovalev, S.M. \&V.M. Kovalev, (2006). Business processes, basic standards of their description. Journal of Directory economist, №11: 245.

Markov, L.S. (2006). Economic clusters: identification and evaluation of the effectiveness and activities. Novosibirsk publishing house SB RAS IE PPO: 68.

Moiseeva, P.K. (2002) .Upravlenie marketing: theory, practice, information technology: the manual. Moscow publishing house «Finance and Statistics»: 304.

Nigmetzyanova, E.S. (2011). Modeling the processes of regional industrial cluster. Journal of Young scientist, №3: 53.

Pogodina, T.P. \& T.V. Zadorova (2009). Evaluation of the competitiveness of the economy and trends clustering regions of the Volga 
Federal District. Journal of Regional Studies, №1: 79.

Porter, M. E. (2006). Competition. Moscow publishing house "Williams":608.

Repin, V.E. \& A.V. Eliferov (2006). Process approach to management. Business process modeling. Moscow publishing house «Standards and Quality»: 92.

Rosenfeld, S. (1992). Clustering of small enterprises. Journal of Bulletin IDS, №3:95.

Semakin, I.E. (2005). Information systems and models. Moscow publishing house «LBZ»: 303.

Shalmina, G.G. (2008). Territorialnye clusters Russia (history, problems and solutions. Journal of Bulletin Tomsk State University. Economy, № 1: 73.

Sirazetdinov, R.T. \& A.A. Brazhkina, (2010). Universal structural model of a typical economic cluster. KSTU: 89.

Tatarkin A.I. \& J.G. Lavrikova (2008). Cluster policy in the region. Journal of Industrial policy in the region, № 8: 76.

Tatarkin, A.I. (2012). The industrial complex of the region using cluster initiatives. Moscow publishing house "Business Inform», № 9:73

Titov, V.I. (2009). Analysis of economic activity of the enterprise. Research Institute of Technology School: 192.

Tsihan T. (2003). Cluster Theory of Economic Development. Journal of Theory and practice of management, №5: 39.

Vakorin, M.P. (2013). Process approach to the management of industrial restructuring. Journal of Bulletin of the University of Finance, №4 (76): 156

Vasiliev, J.P. (1984). Management of intra-system information. Journal of Experience in the United States. Economy: 231.

Womack J.P. \& D. T. Jones (2006). Lean software. How to build an effective and mutually beneficial relationship. Moscow publishing house «Harvard Business Buks»: 272. 